\title{
ENGINEERING SKETCHING AS A VISUALIZATION TOOL - PART DEUX: VISUALIZING ENGINEERING CONCEPTS
}

\author{
M.J. Eggermont, D.M. Douglas, D.J. Caswell, C.R. Johnston, O.R. Fauvel \\ Faculty of Engineering, University of Calgary \\ Phone: +1.403 .210 .9888$ \\ Email:meggermo@ucalgary.ca
}

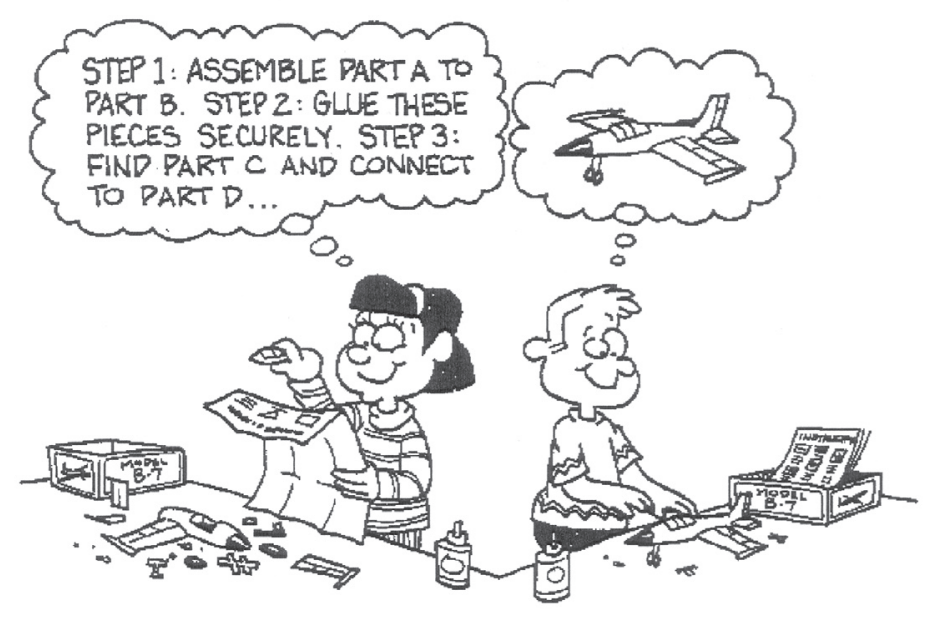

Figure 1. Auditory-Sequential and Visual-Spatial thinking. [1]

\begin{abstract}
Engineering sketching is a method of externalizing the thinking about, and solving of, design problems. Sketch-

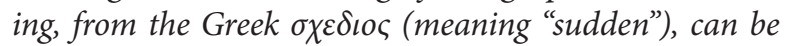
defined as:

1. A simple, rough drawing or design

2. A brief plan or description of major elements.

Sketching exists somewhere between writing and formal drawing as a means of formulating ideas. In the third year of teaching engineering sketching in our first year design course, assignments were given an additional component: the visualization of engineering concepts. This had three motivations:
\end{abstract}

1. Students should be given the opportunity to integrate knowledge from other first year engineering courses

2. Students should be challenged to think spatially

3. Students who were not necessarily strong renderers should be able to do well in the "concept" category.

This paper will discuss how these new components encouraged the students into a more Visual-Spatial (vs) thinking mode. There will be some discussion regarding how vs type students "understand" with respect to more prevalent Auditory-Sequential (ASQ) type students. The goal of visualizing engineering concepts is to bridge the ASQ style of deliveries (from other knowledge-bases) with a more vs style of problem solving. 


\section{Introduction}

"Well, I've made some mistakes. But at least I snagged one of those Michael Graves toilet brushes back in 2004!" [2]

This is the third year the drawing component of the first year design course was offered. We see sketching and drawing practice still as one of the building blocks for idea generation, problem solving and right hemisphere stimulation (visual-spatial). If we are to believe the assertion in Daniel Pink's book A Whole New Mind, North America is on the brink of a new age. Pink refers to this new age as the Conceptual age, following the Information age [Fig. 2].

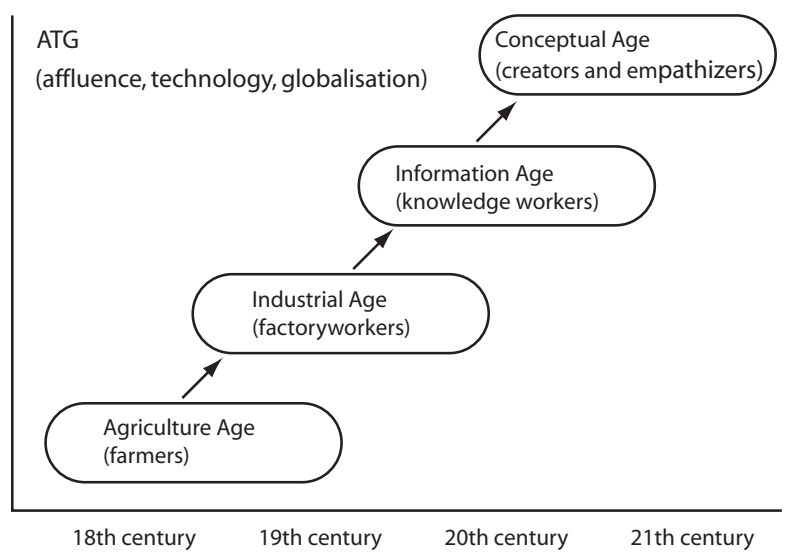

Figure 2. From the Agriculture Age to the Conceptual Age.

In A Whole New Mind, he describes how North American professionals, engineers among them, will have to get ready for this new age. He sees three causes for this much needed shift in thinking: Asia, abundance, and automation. How prepared is North America after answering the following three questions:

1. Can someone overseas do it cheaper?

2. Can a computer do it better?

3. Is what I'm offering in demand in an age of abundance?

Apparently a designer toilet brush is. If the first two answers to the above questions are yes and the third anwser is a resounding no, Pink suggests that we have been neglecting our right hemishere for too long. This part of the brain enables us to "forge relationships rather than execute transactions, it can tackle novel ideas rath- er than solve routine problems and synthesize the big picture rather than analyze a single component"[3]. In order for us to educate well-rounded thinkers, who use the right in conjunction with the left hemisphere (auditory-sequential), Pink points to six areas which he feels stimulate our right hemishere: Design, Story, Symphony, Empathy, Play, and Meaning. "For businesses", he argues, "it's no longer enough to create a product that is reasonably priced and adequately functional - it must also be unique, beautiful and meaningful" [4]. You need your right hemisphere for the latter: "try explaining a designer garbage can to the left hemisphere".

While the second half of Pink's book becomes a bit of a self-help debacle, he has some very valid and probably - by now - well-known points.

The design class is the perfect environment to test some of these concepts. This past year some additional components were added to the (up to this point) relatively straight-forward drawing assignments. Three of these components will be briefly discussed to illustrate how we tried to get students to take these visualization exercises one step further.

\section{More on ASQ and vS}

"The right brain harbours the truth in sensory experiences and by choosing the words to articulate the moment, the left brain becomes the publisher and the curator of meaning." [5]

The Western focus on left-hemisphere and auditory-sequential education stems from Western culture and philosophy. Western thought is "sequential, temporal and analytic compared with Eastern culture and philosophy, which is spatial and holistic."[6] The Euro-American thinks in terms of cause and effect, whereas from an Asian point of view a synchronicity of unrelated events is more appreciated. Language in both cases confirms these differences; Asian language is based on pictures, Western languages "are constructed out of non-meaningful elements - letters of the alphabet." [7]

When left brain thinkers are asked to answer a question, they will look for the right answer based on the facts at their disposal. When right brain thinkers are asked a question, they usually respond with some form of "tell me more/it depends". As all their knowledge is connected, they can see many paths to differing answers and they want more information to help them decide which path to take to the required answer. This divergent thinking is the hallmark of creativity, but may not be un- 


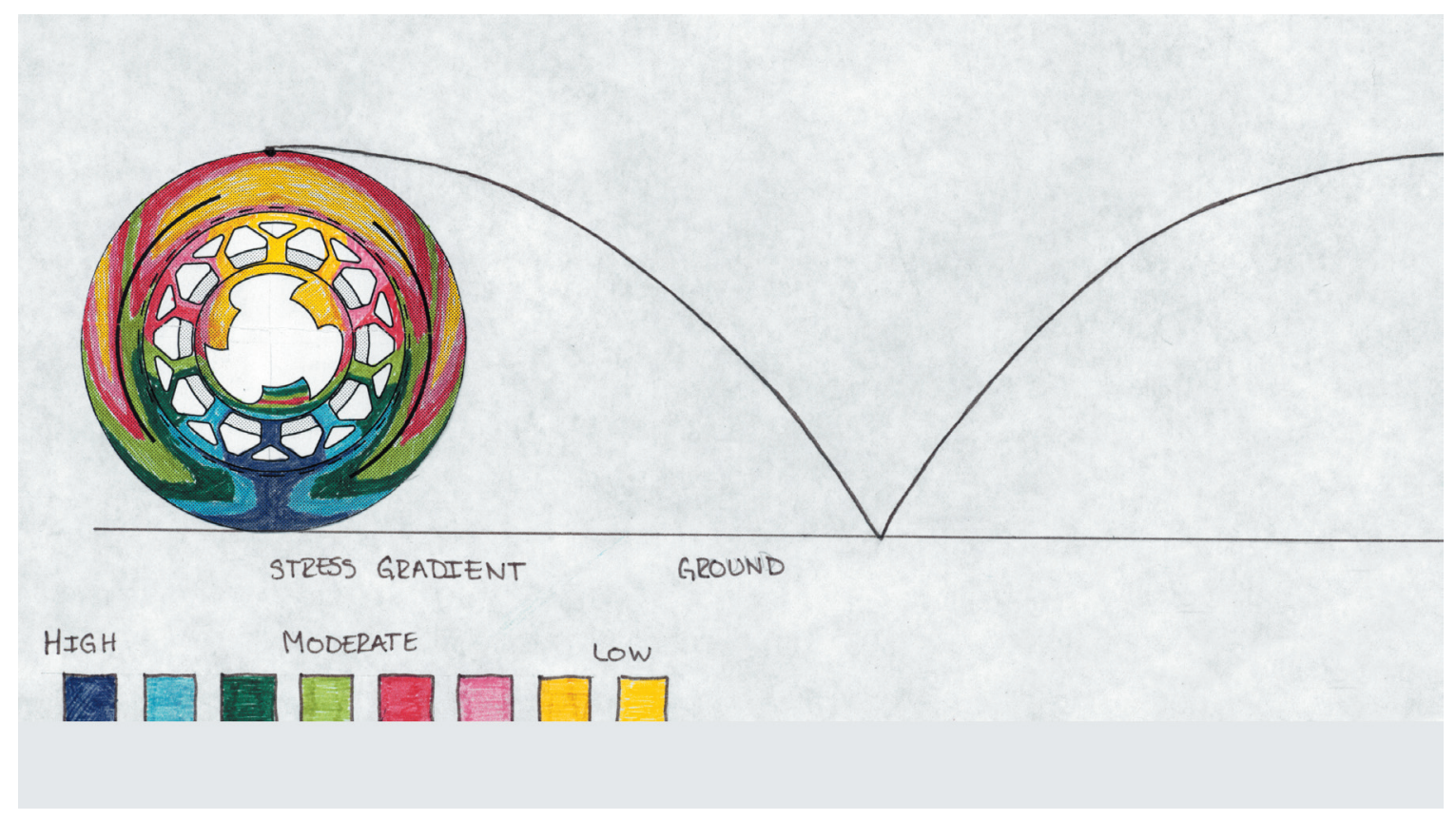

Figure 3. Stress and loci assignment/student work.

derstood in school where achievement is often seen as having the right answer. As Jeffery Freed says, "because one of the attributes of right-brained thinking is a nonsequential divergent form of thinking, these minds often veer into unusual and different territory. This can result in illogical or often unsubstantiated conclusions. On the other hand, they may view a problem from an entirely different angle, leading to new breakthroughs and discoveries." [8]

\section{Component 1: Stress and Loci}

Students were asked to draw a sectioned skateboard wheel in isometric and in three view orthographic. The second half of the assignment was added to see if students could show visually the stresses in a wheel when someone stands on top of a stationary skateboard. The use of colour, arrows, and shading was encouraged [Fig. 3].

They were also asked to show the path (locus/loci) a point on the outside rim of the wheel makes while the skateboard is rolling at a constant speed. They were asked to consult their Statics \& Dynamics professors in an effort to show that all engineering questions do not cease to exist at the door of the lab, and can flow from one classroom into the next [Fig. $5 \& 6$ ].

\section{Component 2: Movement Analysis}

In this assignment students were asked to choose a scene of a movie, a 'play' in a sports game, or sequence of events they had experienced themselves. They were then asked to show this movement in a three-dimensional oblique space and a two-dimensional orthographic side or top view [Fig. $7 \& 8$ ].

\section{Component 3: Design Style Analysis}

Students were introduced to the history of design from about 1850 (around about the time that engineers started to have an influence on design) to the present. They were introduced to artistic, craft and high-tech influenced styles [Fig. 4]. Students were asked in their assignments to pick an object from one of the design styles introduced, draw some details, and explain the object using their first year engineering knowledge from all courses. They were asked to look at the two aspects of design as so called by John Heskett: utility and significance [Fig. 9 \& 10]. Kathryn Henderson, in On Line and On Paper, describes this as follows: "Aesthetics and standards are equally important in engineering and both can be read in functional and symbolic terms. The line between aesthetics and standards is drawn mainly by the distinction 
that standards embody the specific rules of design work while aesthetics encompass the unwritten rules that distinguish mediocre work from quality design.”[9]

\section{Conclusion}

If, as Daniel Pink asserts, we are heading towards a conceptual age, students should be introduced to the possiblity of a shift. The class assignments were designed to encourage students to solve problems in a more intuitive manner. By introducing visualizations of stresses, movement, and other engineering design concepts, students were given the opportunity to stimulate the 'big picture' right hemisphere. The purpose of these exercises is not to separate the brain into some Carthesian mind/body duality, but to prepare future engineers for a rapidly changing society where computers are faster, abroad is cheaper, and your 'whole' brain is the only real commodity.

\section{References}

[1] Silverman, Linda K. The visual-spatial learner: An Introduction, 2003, p. 6.

[2] Pink, Daniel H., A Whole New Mind - Moving from the Information Age to the Conceptual Age, Riverhead Books, New York, 2005, p. 35.

[3] ibid, p.39.

[4] ibid, p. 33 .

[5] Blackburn, Emma. "Free Your Mind: A Right Brain Future", p. 19.

[6] Silverman, Linda K. "Effective Techniques for Teaching Highly Gifted Visual-Spatial Learners", p. 1.

[7] ibid, p. 1.

[8] Freed, J. “Teaching Right: Techniques for Visual Spatial Gifted Children". Understanding Our Gifted. January/ February, 1996.

[9] Henderson, Kathryn. On Line and On Paper Visual Representations, Visual Culture, and Computer Graphics in Design Engineering, The MIT Press, Cambridge, 1999, p. 149.

Design styles timeline. [From: Fiell, Charlotte \& Peter, Design of the 2oth century,Benedickt Taschen Verlag GmbH, Köln, 752.]

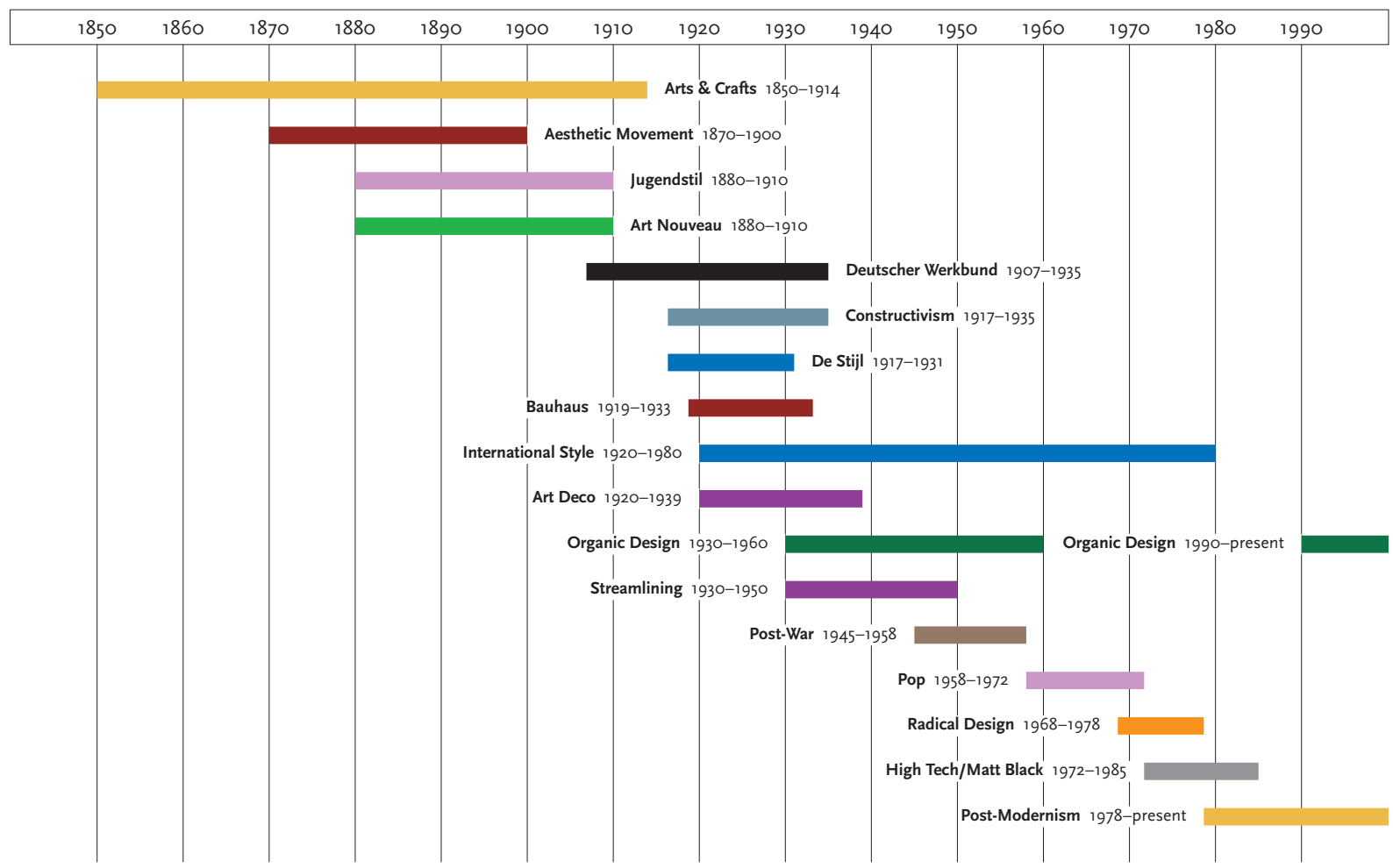

Figure 4. Design history as presented to the first year design class. 


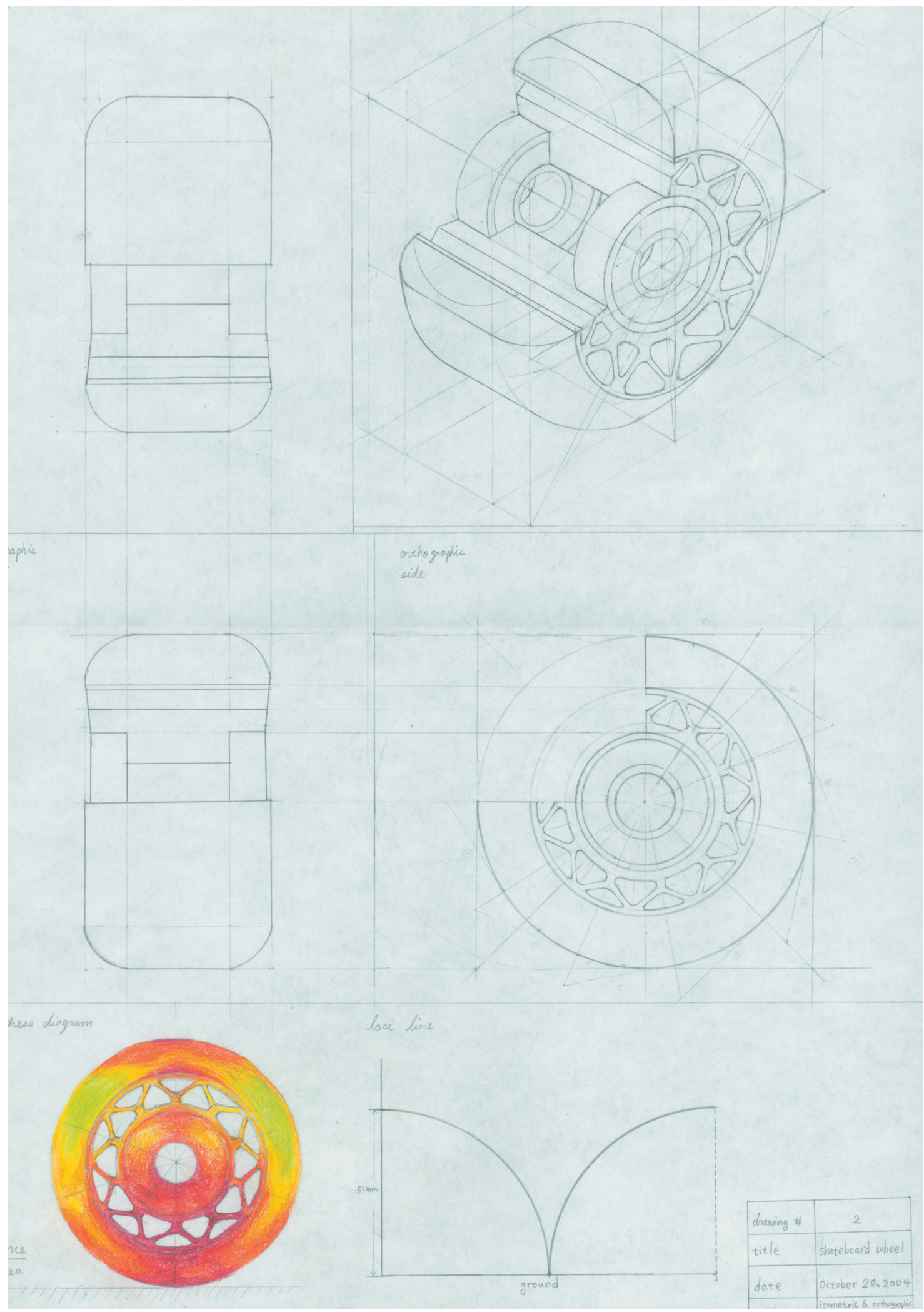

Figure 5. Stress and loci assignment/student work.

Marjan Eggermont • 5 


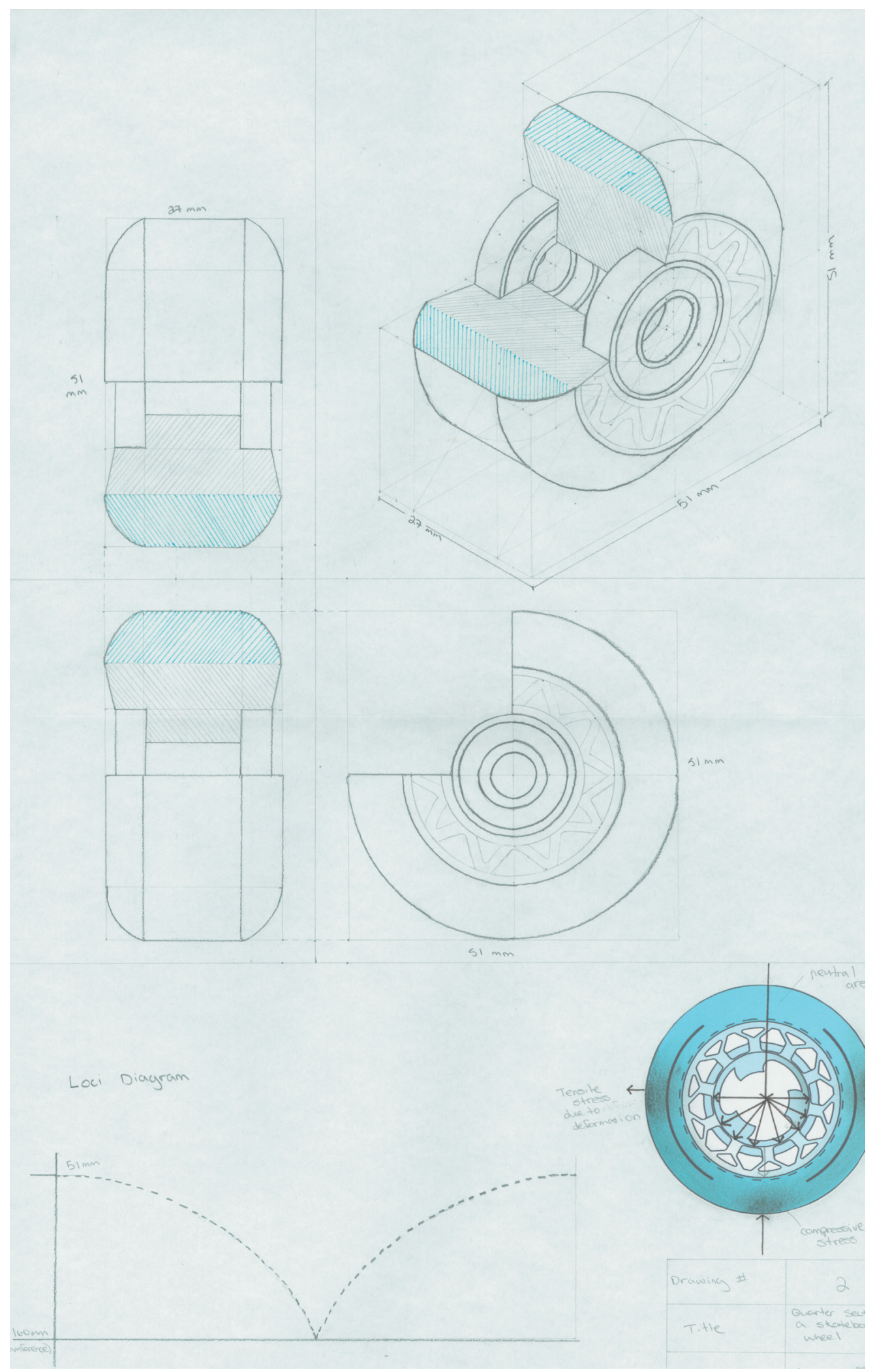

Figure 6. Stress and loci assignment/student work.

Marjan Eggermont • 6 


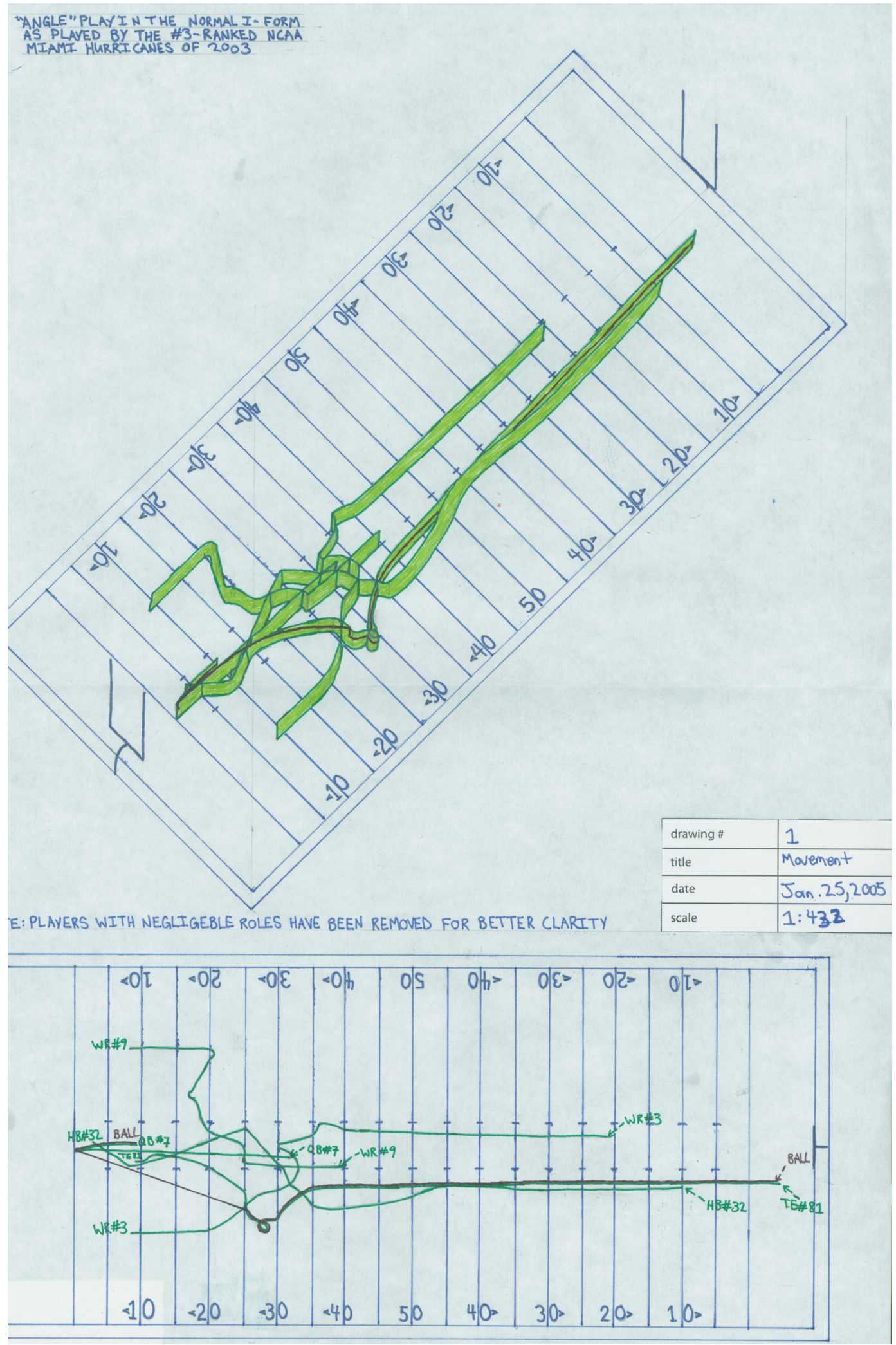

Figure 7. Two and three-dimensional movement analysis/student work. 

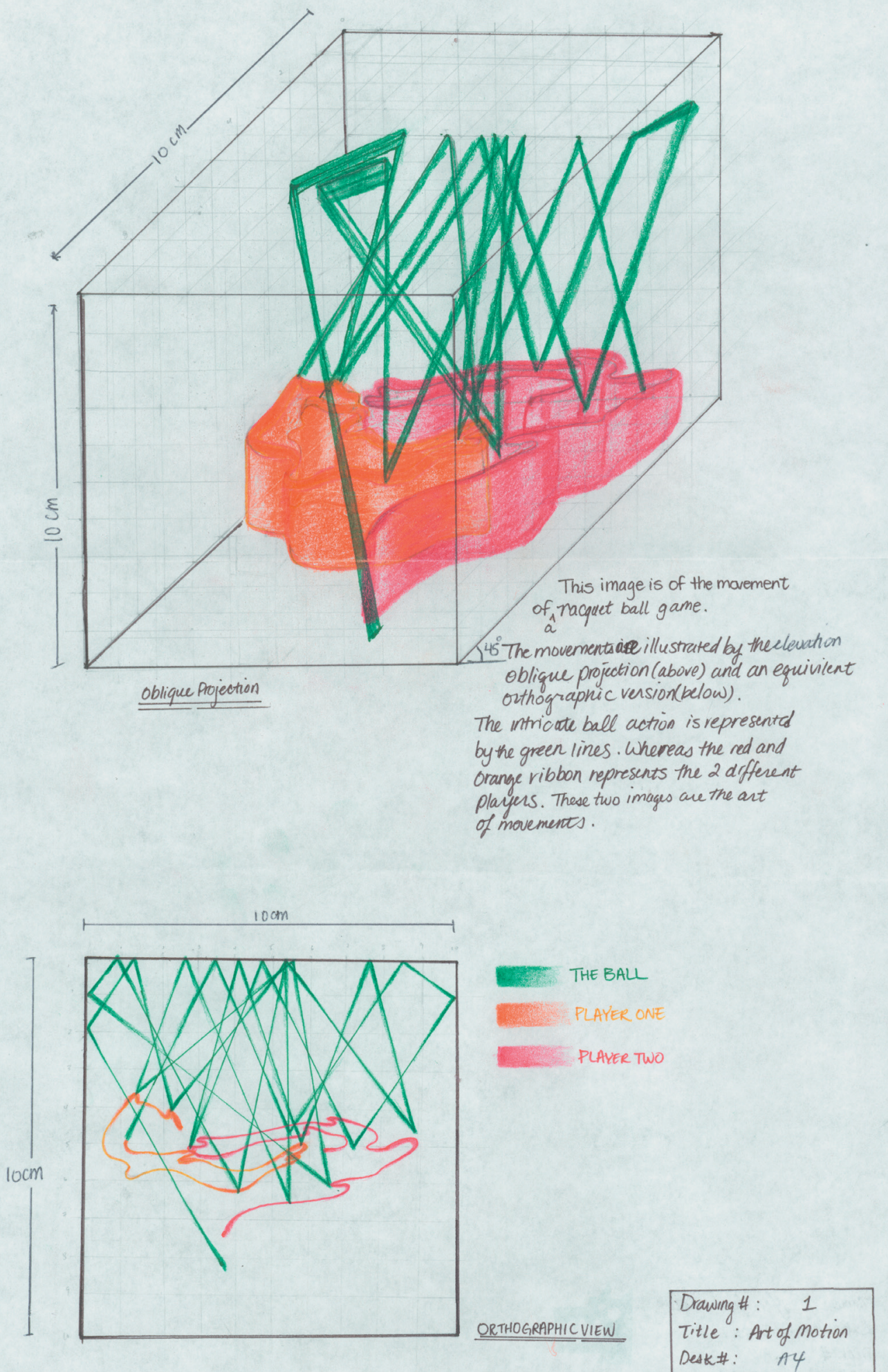

Figure 8. Two and three-dimensional movement analysis/student work. 


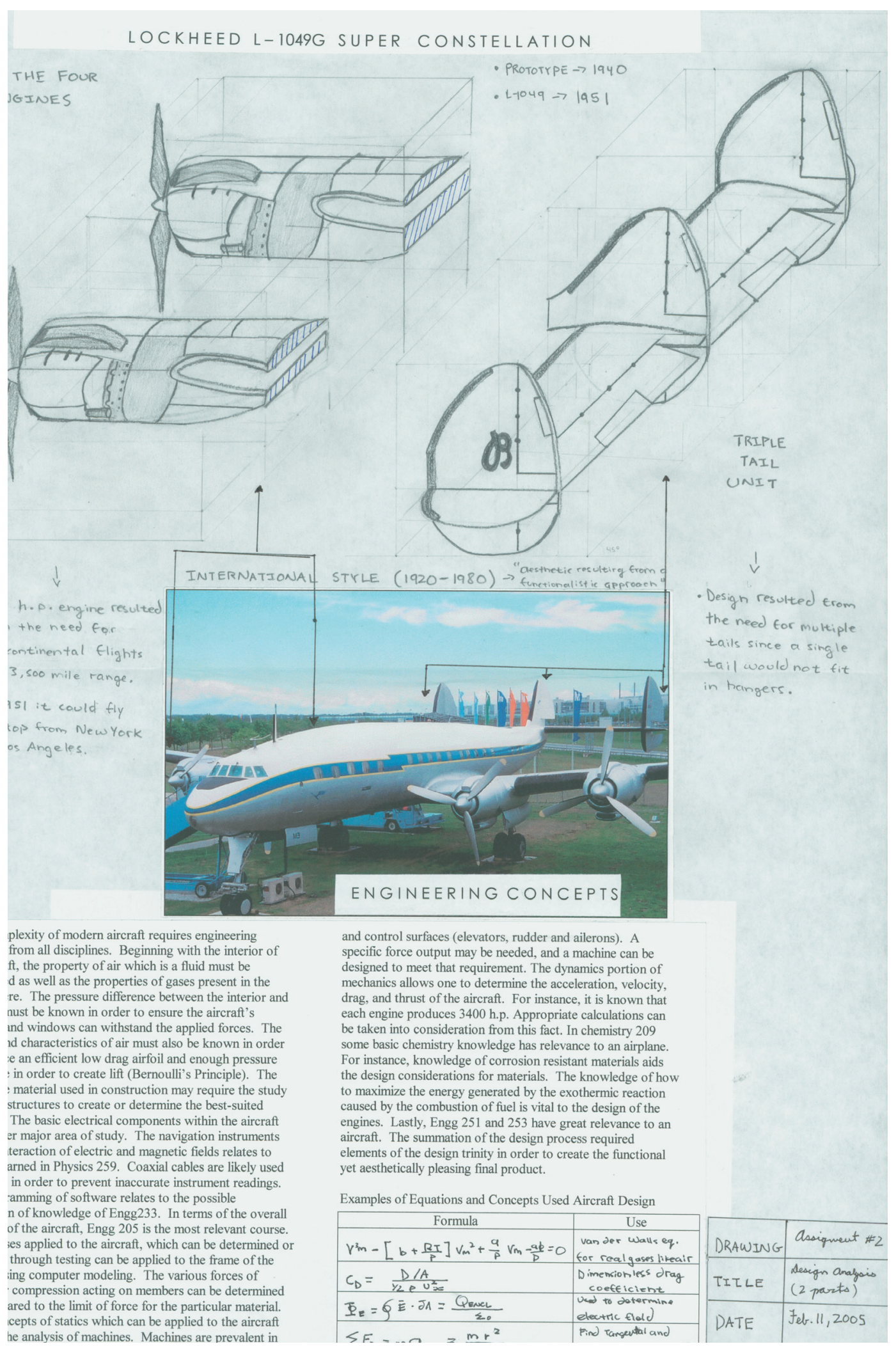

Figure 9. Design style analysis/student work.

\section{Marjan Eggermont • 9}




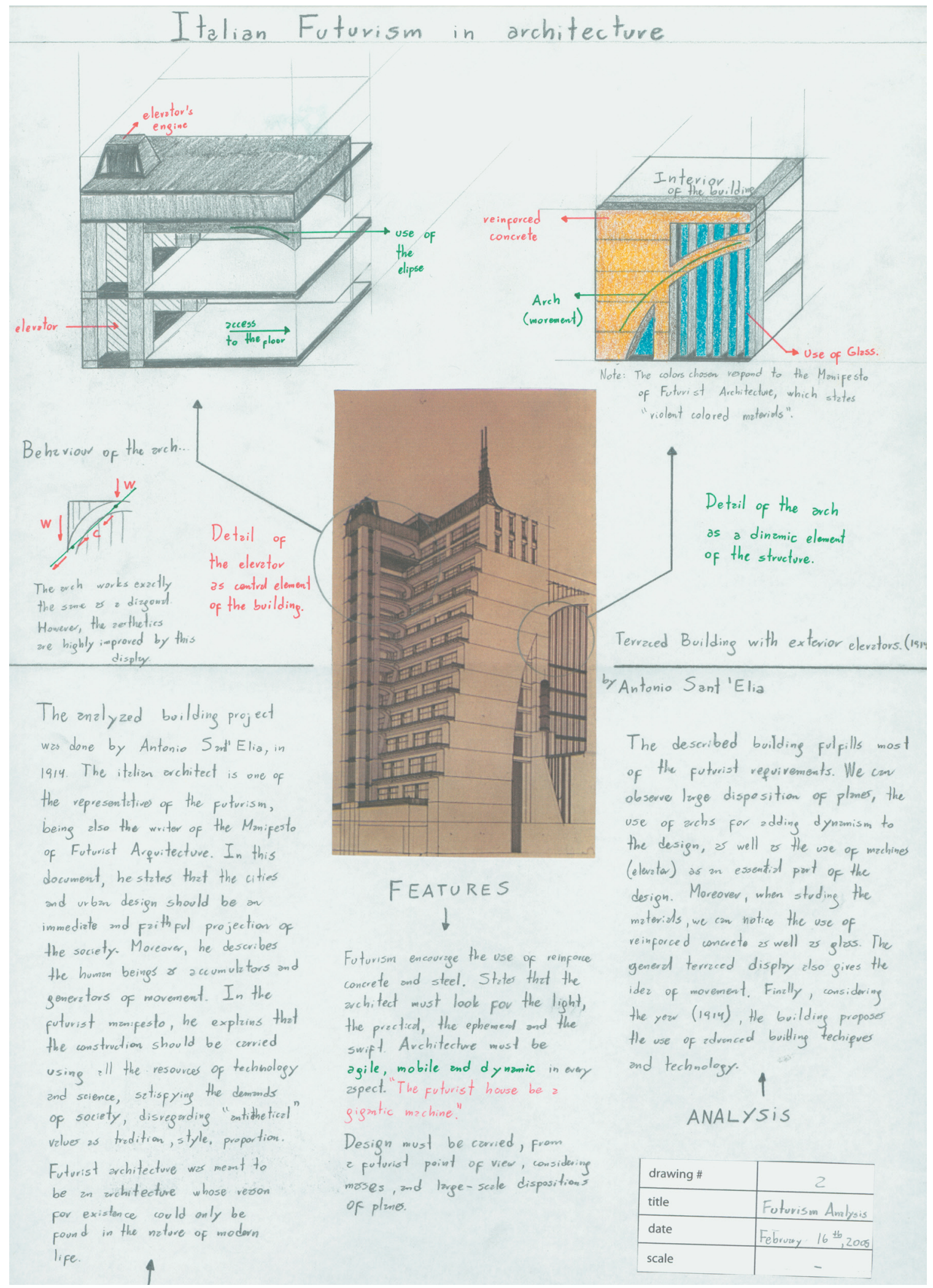

Figure 10. Design style analysis/student work. 